\title{
Determinants of Using the Modern Health Care in the Bagira Health Zone: Cases of Children Under 5 Years Old with Malaria
}

\section{Eugène Kwamba ${ }^{1,5,6}$, Christian Molima1 ${ }^{1}$ Johanna Karemere ${ }^{2}$, Safari Joseph Balegamire ${ }^{3,4}$ and Hermès Karemere ${ }^{1,7 *}$}

${ }^{1}$ Regional School of Public Health, Catholic University of Bukavu (UCB), Bukavu, South Kivu, Democratic Republic of Congo

${ }^{2}$ National Malaria Control Program, DRC Ministry of Health, Kinshasa, Gombe, Democratic Republic of Congo

${ }^{3}$ Department of Medicine Social and Preventive, E School of Public Health, Montreal University, Montreal, Quebec, Canada

${ }^{4}$ Department of Nutrition, Natural Sciences Research Center of Lwiro, Bukavu, Democratic Republic of Congo

${ }^{5}$ General Reference Hospital (GRH) of Mweka, Mweka/Tshikapa, Kasaï, Democratic Republic of Congo

${ }^{6}$ Higher Institute of Medical Techniques (ISTM), Kakenge/Kasaï, Mweka/Tshikapa, Kasaï, Democratic Republic of Congo

${ }^{7}$ Université du Cinquantenaire de Lwiro, Sud-Kivu, Democratic Republic of Congo

*Corresponding Author: Hermès Karemere, Regional School of Public Health, Catholic University of Bukavu (UCB), Bukavu, South Kivu, Democratic Republic of Congo.
Received: July 09, 2021

Published: September 28, 2021

C All rights are reserved by Hermès Karemere., et al.

\begin{abstract}
Introduction: Bagira Health area is characterized by a decline in the rate of use of curative health care between 2014 and 2018 while the prevalence of malaria was on the rise. This statement justifies the present study, which identified the specific determinants of the use of malaria-related children under 5 years in the Health area.

Methodology: This is a cross- sectional analysis conducted in the Bagira Health area. An investigation was conducted with 303 households from the systematic, two-degree, systematized random sampling technique. The Data analysis used descriptive statistics and the Logit multinomial model.

Results: The specific determinants identified in the use of health care in the case of malaria in the less than five years in the health area of Bagira are: the orphan parental status (19.70\% of the probability of access to the public health center); the knowledge of antimalaria by parents ( $24 \%$ of the probability of access to public health cent e rs); follow-up at home ( $70.30 \%$ probability of use of the private health center) and the method of payment including the per-slice package $(73.40 \%$ of the probability that private centers are used).

Conclusion: The continued improvement of the quality of care, taking into account the determinants identified with a particular focus on the follow-up of sick children during and after treatment, should be strengthened in order to increase the use of curative care in Bagira.
\end{abstract}

Keywords: Determinants; Health Services; Malaria; Logit Multinomial Model; Children Under 5 Years; South-Kivu; Democratic Republic of Congo 


\section{Introduction}

Globally, nearly 5.6 million children die before their fifth birthday in 2016, or 15,000 every day, from preventable causes, mainly pneumonia, diarrhea and malaria [1]. This situation affects health, a productivity factor for the well-being of the population [2]. The World Health Organization (WHO) recognizes the right to health as one of the fundamental rights of every human being. In particular, it presupposes being able to access healthcare in a timely manner and to be able to finance treatment and other medical acts $[3,4]$. In addition, the third objective of sustainable development [5] prioritizes the issue of "good health and well-being" of the entire world population.

People in developing countries struggle to achieve good health and well-being because they are frequently threatened by endemoepidemic diseases such as malaria, and which they are not able to systematically carry out a consultation in a health structure because of limited financial resources. Self-medication, easily accessible and inexpensive, constitutes an essential alternative $[4,6]$, sometimes fatal [7].

It is also reported that for cases of severe malaria encountered in health facilities, parents are slow to seek treatment for their child under 5 years old following numerous treatment attempts with other therapists outside the national health system [8]. In this context, it is demonstrated that parents, and especially mothers, have a speedy face-by-face the fever reaction as a major sign of the child's malaria [9]. However, despite the parents' (especially mothers) feeling of competence regarding to infectious signs such as fever [10], many factors such as distance, waiting time, financial constraints [11], the lack of confidence in the quality of services, the shortage of medicines and the behavior of health workers have led communities to go less to health facilities in Africa and to resort to the sector instead private or informal holding unsuitable drugs of poor quality [12].

This situation in Africa does not spare the Democratic Republic of Congo (DRC) ranked among the 6 countries in the world accounting for $50 \%$ of world infant mortality, after India, Nigeria, China, Pakistan and before Ethiopia [13]. The infant mortality rate is $43 \%$ [13]. So there are 5 children under 5 who die every minute [13]. Among the main causes are malaria through several factors including the low use of curative health services (around 25\%); the use of drugs of poor quality and of questionable origin in the community and households, abusive self-medication, ignorance of dan- ger signs, late consultations in health facilities (HF), weak involvement of the community $[14,15]$. In general, it appears that at least two-thirds of patients therefore do not resort to the health system to obtain care [13]. This situation also affects the province of South Kivu in the Democratic Republic of Congo (DRC), including the Bagira Health Zone (HZ), hit by this situation (last in terms of use of care among the weak with a rate of $21.8 \%$ ). The rate of use of curative care is low and, declining since 2017 , while the prevalence of malaria shows an increasing trend, as presented in the figure 1 below.

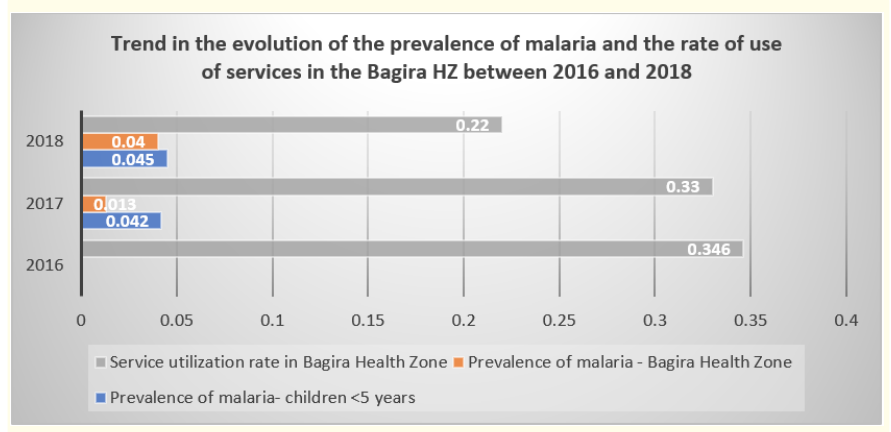

Figure 1: Use of curative care in the Bagira Health Zone from 2016 - 2018.

Use of curative care: decreasing trend, prevalence of malaria: increasing trend. (Source: Bagira Health Zone: 2016, 2017 and 2018 Annual Reports).

Some studies on the demand for and supply of health care carried out in the DRC, in particular in Bagira [16], have identified the determinants of the use of health care, without being specific to children under 5 years old suffering from malaria $[17,18]$. Other work carried out are limited on therapeutic routes and other traditional factors already known [19] without an interest in monitoring during and after treatment and at the onset of complications in children under 5 years old with malaria and knowledge of antimalarials by heads of households.

This is how we asked ourselves the following question: "What would influence the use of care for children under 5 with malaria in the Bagira Health Zone?". The answer to this question is the objective of this study. It would make it possible to know the therapeutic route according to the health facilities and the specific determinants of the use of health care for children under 5 years with malaria, in the Bagira HZ. 


\section{Materials and Methods}

\section{Description of the study area}

The study was carried out in the Bagira HZ in the DRC. The $\mathrm{HZ}$ is composed of 22 Health facilities (HF) including health posts, distributed on 8 health areas (HA) and a General Referral Hospital (GRH). The total population of children under 5 years in 2019 was of 27156 [20]. According to HZ development plan of Bagira HZ 2016-2020, the low utilization of curative care is among the main problems. The situation epidemiological class malaria second after pulmonary infections from the side of morbidity and fourth side mortality [21]. The art rooms prayers, the selfmedication, the belief in the poisoning are among us and customs related to the health of the population [21].

Type of study, study population, sampling, calculation of sample size and inclusion and exclusion criteria

This is a cross-sectional study in analytical referred consisting of a household survey of children who have a fever episode in the last quarter of 2019 in the area of Bagira Health Zone.

Sampling was systematic random and stratified to two stages.

The minimum sample size was of 303 households in the form of SCHWARTZ:

$$
\left(\mathrm{n} \geq \frac{\mathrm{Z} \alpha^{2} \mathrm{p}(1-\mathrm{p})}{\mathrm{d}^{2}}\right)
$$

Were included in our sample, all households containing children under 5 and having experienced at least one episode of fever in the last month preceding our survey; and were excluded from our study:

- Any household without children under 5 years old.

- $\quad$ Any household with children under 5 who have not had a febrile episode during the last month preceding our survey in January 2020.

Data collection used a survey questionnaire administered to the heads of the households concerned, after a pre-test carried out with 30 households in the Kadutu Health Zone, a neighboring HZ.

The data was entered and encoded in an input mask using Sphinx quali software, V5demo. The statistical analysis began with a description of quantitative and qualitative variables collected in terms of means, proportions and standard deviation.
For the impact of the explanatory variables on the use of care, we used a Logit model [22,23] which made it possible to estimate the probabilities of any household using modern health care in one of the facilities, given that our dependent variable is qualitative.

For ethical reasons, the protocol for this study was presented to the Bagira Health Zone management team for approval and agreement for the completion of the household survey within the HZ. Free and verbal informed consent was requested from the heads of the households concerned in strict compliance with confidentiality measures.

\section{Results}

The study involved a total of 303 subjects each representing a household spread over 8 Health Areas in the Bagira health zone.

\section{Socio-demographic characteristics}

It has been shown in table 1 that the male sex is predominant (85.48\%) for heads of households with an average age of children under 5 years of 1.75 years. The sample was composed mainly of married people ( $87.00 \%$ of cases), farmers (15.51\% of the sample) and unemployed people (14.85\% of cases).

\begin{tabular}{|c|c|c|c|}
\hline Variable & $\begin{array}{c}\text { Informal } \\
\text { care }\end{array}$ & $\begin{array}{c}\text { Care in inte- } \\
\text { grated HF }\end{array}$ & Total \\
\hline \multicolumn{4}{|l|}{ Sex } \\
\hline Feminine & $25(56.81)$ & $18(40.90)$ & $44(14.52)$ \\
\hline Male & 145 (55.98) & $114(44.01)$ & 259 (85.48) \\
\hline Age & $36.52(6.60)$ & $38.31(14.34)$ & $37.43(5.23)$ \\
\hline \multicolumn{4}{|l|}{ Profession } \\
\hline Unemployed & $18(40.00)$ & $27(60.00)$ & 45 (14.85) \\
\hline State official & $8(42.10)$ & $11(57.89)$ & $19(6.27)$ \\
\hline Private & $26(59.09)$ & $18(40.90)$ & $44(14.52)$ \\
\hline Farmer & $27(57.44)$ & $20(42.55)$ & 47 (15.51) \\
\hline $\begin{array}{c}\text { Service } \\
\text { Independent }\end{array}$ & 15 (57.69) & $11(42.30)$ & $26(8.58)$ \\
\hline Small business & $69(60.00)$ & $46(40.00)$ & 115 (37.95) \\
\hline Other & $100(100.00)$ & $00(00.00)$ & $7(2.31)$ \\
\hline \multicolumn{4}{|l|}{ Civil status } \\
\hline Married & $36(13.63)$ & $116(43.93)$ & $264(87.00)$ \\
\hline Divorced & $11(68.75)$ & $5(31.25)$ & $16(5.28)$ \\
\hline Widower & $3(33.33)$ & $6(66.66)$ & $9(2.97)$ \\
\hline Free Union & $8(57.14)$ & $6(42.85)$ & $14(4.62)$ \\
\hline \multicolumn{4}{|l|}{ Religion } \\
\hline Catholic & 77 (58.77) & $54(41.22)$ & $131(43.23)$ \\
\hline Protestant & 69 (58.97) & $48(41.02)$ & $117(38.6)$ \\
\hline Muslim & $5(38.46)$ & $8(61.53)$ & $13(4.29)$ \\
\hline
\end{tabular}




\begin{tabular}{|c|c|c|c|}
\hline $\begin{array}{c}\text { Brahmanist } \\
\text { nesses }\end{array}$ & $8(53.33)$ & $7(53.84)$ & $15(4.95)$ \\
\hline Kimbanguist & $1(14.28)$ & $6(85.71)$ & $7(2.31)$ \\
\hline Anglican & $4(66.66)$ & $2(33.33)$ & $6(1.98)$ \\
\hline Tribe & & & $14(4.62)$ \\
\hline Bashi & $110(58.82)$ & $77(41.17)$ & $187(61.7)$ \\
\hline Barega & $35(53.03)$ & $31(46.96)$ & $66(21.78)$ \\
\hline Batembo & $25(53.19)$ & $22(46.8)$ & $47(15.51)$ \\
\hline Other & $00(00 / 00)$ & $3(100.00)$ & $3(0.99)$ \\
\hline Study level & & & $41(13.53)$ \\
\hline No & $13(31.70)$ & $28(68.29)$ & $123(40.59)$ \\
\hline Certificate p & $79(64.22)$ & $44(35.77)$ & $104(34.32)$ \\
\hline State diploma & $63(60.57)$ & $41(39.42)$ & $35(11.55)$ \\
\hline Superior & $15(42.85)$ & $20(57.14)$ & $1.02(0.85)$ \\
\hline Returned & $0.81(0.52)$ & $1.19(1.08)$ & $1.75(0.72)$ \\
\hline Child age $<5$ & $1.73(3.07)$ & $1.75(0.72)$ & \\
\hline years & & & \\
\hline
\end{tabular}

Table 1: Socio-demographic characteristics of households. Legend: 0 percentage and standard deviation.
Reasons for the choices of the person in charge in the explanation of the choices of modern structures

When a head of household knows antimalarial drugs, his probability of using public centers and hospitals increases by $24.5 \%$ and $6.9 \%$ respectively; the presence of the traditional healers decreases the likelihood of an appeal in the hospital (6.9\%); a good home increases the likelihood of an appeal to private health centers s (20.3\%) as shown in table 1.

Factors associated with structures in explaining the choices of modern structures

The main factors identified as associated structures in explaining the choices made by the art households seeking care are: distance, method of payment, patient monitoring and drugs availability.

The table 3 shows that when the distance between households and other health facilities increases, the probability for households

\begin{tabular}{|c|c|c|c|c|c|c|c|}
\hline \multirow{2}{*}{ Variables } & \multicolumn{3}{|c|}{ Coefficient } & \multicolumn{4}{c|}{ Marginal effects } \\
\cline { 2 - 8 } & CSPC & HP & CSP & CSPC & DP & HP & CSP \\
\hline Medication knowledge & $15.69^{* * *}$ & $16.12^{* * *}$ & 0.745 & $0.245^{* *}$ & -0.200 & $0.0690^{* * *}$ & 0.115 \\
\hline & $(1.798)$ & $(2.095)$ & $(1.193)$ & $(0.0282)$ & $(0.261)$ & $(0.0184)$ & $(0.262)$ \\
\hline Care places : home & $14.51^{* * *}$ & $15.81^{* * *}$ & $13.45^{* * *}$ & 0.132 & $-0.173^{* * *}$ & 0.283 & 0.241 \\
\hline & $(1.555)$ & $(1.899)$ & $(1.200)$ & $(0.215)$ & $(0.0282)$ & $(0.295)$ & $(0.293)$ \\
\hline Traditional practitioner & $-17.45^{* * *}$ & $-17.13^{* * *}$ & -1.661 & $-0.248^{* * *}$ & 0.421 & $-0.0690^{* * *}$ & -0.104 \\
\hline & $(0.759)$ & $(1.023)$ & $(1.084)$ & $(0.0284)$ & $(0.265)$ & $(0.0186)$ & $(0.267)$ \\
\hline & $-1.224^{* *}$ & -1.071 & -0.387 & $-0.127^{*}$ & 0.0812 & -0.0290 & -0.0752 \\
\hline Loan & $(0.510)$ & $(0.658)$ & $(0.416)$ & $(0.0497)$ & $(0.0581)$ & $(0.0261)$ & $(0.0726)$ \\
\hline & 0.216 & -1.756 & 0.133 & 0.0329 & -0.00970 & $-0.0589^{* *}$ & 0.0357 \\
\hline Reason of choice : low cost & $(0.708)$ & $(1.149)$ & $(0.643)$ & $(0.109)$ & $(0.0669)$ & $(0.0205)$ & $(0.126)$ \\
\hline & 0.246 & $-2,243^{* *}$ & 0.832 & 0.0511 & -0.0587 & $-0.09322^{* * *}$ & $0.203^{*}$ \\
\hline Welcoming & $(0.621)$ & $(1.124)$ & $(0.523)$ & $(0.0715)$ & $(0.0449)$ & $(0.0222)$ & $(0.0838)$ \\
\hline & $0.976^{*}$ & -0.806 & $1.009^{* *}$ & 0.0432 & $-0.0960^{*}$ & $-0.0837^{* *}$ & 0.137 \\
\hline Closer & $(0.524)$ & $(0.623)$ & $(0.464)$ & $(0.0680)$ & $(0.0440)$ & $(0.0275)$ & $(0.0800)$ \\
\hline & $2.201^{*}$ & -0.500 & 1,662 & 0.160 & $-0.123^{* *}$ & $-0.0619^{* *}$ & 0.0247 \\
\hline Availability & $(1.171)$ & $(1.704)$ & $(1.128)$ & $(0.132)$ & $(0.0397)$ & $(0.0200)$ & $(0.136)$ \\
\hline & $-15.45^{* * *}$ & $-15.71^{* * *}$ & -0.118 & & & & \\
\hline Constant & $(1.831)$ & $(2.117)$ & $(1.228)$ & & & & \\
\hline
\end{tabular}


Determinants of Using the Modern Health Care in the Bagira Health Zone: Cases of Children Under 5 Years Old with Malaria

\begin{tabular}{|c|c|c|c|c|c|c|}
\hline Pr & & & & 0.22 & 0.14 & \\
\hline LR STAT (23) & 50,715 & $\mathrm{pr}=0.001$ & & & & \\
\hline$-\ln$ L & $-314,183$ & & & & \\
\hline Pseudo- R 2 & 0.08 & & & & \\
\hline AIC: & 2,467 & & & & \\
\hline BIC: & $-692,195$ & & & & \\
\hline NOT & 256 & 256 & 256 & & \\
\hline
\end{tabular}

Table 2: The reasons for the choice of head in explaining the choice of modern structures.

Legend: CSPC: Public Health Center; CSP: Private Health Center; DP: Private Dispensary; HP: Hospital; (): Standard Error; ${ }^{*}: \mathrm{p}<0.05,{ }^{* *}: \mathrm{p}<$ $0.1,^{* * *}: \mathrm{p}<0.01$.

to use private clinics increases by $4.40 \%$. The more the cost of care increases, the probability that hospitals will be used becomes higher (26.10\%). Direct lump sum payment reduces the likelihood of using public health centers (4.30\%), hospitals (13.40\%) and private health centers $(26.60 \%)$.

\begin{tabular}{|c|c|c|c|c|c|c|c|}
\hline \multirow[t]{2}{*}{ Variables } & \multicolumn{3}{|c|}{ Coefficient } & \multicolumn{4}{|c|}{ Marginal effects } \\
\hline & CSPC & HP & CSP & CSPC & DP & HP & CSP \\
\hline \multirow[t]{2}{*}{ Distance to HF } & $-0.539 *$ & $-0.841^{* *}$ & -0.429 & $-0.00297 *$ & $0.0442^{*}$ & -0.0718 & -0.0247 \\
\hline & $(0.297)$ & $(0.348)$ & $(0.266)$ & $(0.0549)$ & $(0.0198)$ & $(0.0535)$ & $(0.0279)$ \\
\hline \multirow[t]{2}{*}{ Transport } & -1.609 & 0.00419 & -0.288 & $-0.373^{*}$ & 0.0653 & -0.197 & 0.110 \\
\hline & $(1.184)$ & $(1.138)$ & $(1.097)$ & $(0.162)$ & $(0.0824)$ & $(0.106)$ & $(0.0810)$ \\
\hline \multirow[t]{2}{*}{ Cost of care } & -0.322 & $1.293^{* *}$ & 0.260 & $-0.252^{* *}$ & -0.0178 & $0.261^{* * *}$ & 0.00858 \\
\hline & $(0.538)$ & $(0.609)$ & $(0.479)$ & $(0.0850)$ & $(0.0371)$ & $(0.0739)$ & $(0.0413)$ \\
\hline \multirow{2}{*}{$\begin{array}{c}\text { Direct package payment } \\
\text { method }\end{array}$} & $-14.79 * * *$ & $-15.52 * * *$ & $-16.01 * * *$ & $-0.0432 *$ & $0.357^{* * *}$ & $-0.134^{*}$ & -0.266 \\
\hline & $(1,650)$ & $(1.470)$ & $(1.553)$ & $(0.208)$ & $(0.0895)$ & $(0.142)$ & $(0.149)$ \\
\hline \multirow[t]{2}{*}{ Quality of care index } & $1.046^{* *}$ & 0.202 & -0.105 & $0.248^{* *}$ & -0.0415 & 0.0755 & $-0.131^{*}$ \\
\hline & $(0.494)$ & $(0.457)$ & $(0.347)$ & $(0.0957)$ & $(0.0347)$ & $(0.0754)$ & $(0.0515)$ \\
\hline \multirow[t]{2}{*}{ Drug availability } & $-17.01 * * *$ & $-17.45^{* * *}$ & $-14.93 * * *$ & -0.174 & $0.251^{* *}$ & -0.238 & $-0.161^{*}$ \\
\hline & $(2.366)$ & $(2,480)$ & $(2.515)$ & $(0.190)$ & $(0.0856)$ & $(0.181)$ & $(0.0687)$ \\
\hline \multirow{2}{*}{$\begin{array}{l}\text { Follower from disp en- } \\
\text { saire. }\end{array}$} & $-18.62 * * *$ & $-19.99 * * *$ & $-35.56 * * *$ & $-0.181^{* *}$ & $0.997^{* * *}$ & $-0.113^{* *}$ & $-0.703^{* * *}$ \\
\hline & $(0.719)$ & $(1.592)$ & $(1.597)$ & $(0.0587)$ & $(0.00313)$ & $(0.0353)$ & $(0.0703)$ \\
\hline \multirow[t]{2}{*}{ Constant } & $48.36^{* * *}$ & $21.78^{* *}$ & 33.39 *** & & & & \\
\hline & $(9.713)$ & $(9.738)$ & $(9.040)$ & & & & \\
\hline $\operatorname{Pr}$ & & & & 0.46 & 0.09 & 0.24 & 0.21 \\
\hline LR STAT (20) & 139.62 & $\mathrm{pr}=0.000$ & & & & & \\
\hline$-\ln \mathrm{L}$ & $-211,614$ & & & & & & \\
\hline Pseudo- R 2 & 0.330 & & & & & & \\
\hline AIC: & 1.906 & & & & & & \\
\hline BIC: & $-490,253$ & & & & & & \\
\hline NOT & 174 & 174 & 174 & 174 & 174 & 174 & 174 \\
\hline
\end{tabular}

Table 3: Factors associated with structures in explaining the choices of modern structures.

Legend: CSPC: Public Health Center; CSP: Private Health Center; DP: Private Dispensary; HP: Hospital; Standard errors in parentheses ${ }^{*}$ p < $0.05,{ }^{* *} \mathrm{p}<0.01,{ }^{* * *} \mathrm{p}<0.001$. 
Characteristics of children in the explanation of the choices of modern structures

A few characteristic determinants of children have significantly explained the use of care, these are: number of children under 5 in a household, parental status of the sick child, severity of the disease, occurrence of complications.
The increase in episodes of illness increases the probability of going to a health center more than to a private dispensary (3.8\%). The age of the sick child decreases in the increase in the probability of going to a public health center, hospital and private health center $(0.1 \% ; 0.3 \% ; 0.8 \%)$ than that of going to a private dispensary.

\begin{tabular}{|c|c|c|c|c|c|c|c|}
\hline \multirow[t]{2}{*}{ Variables } & \multicolumn{3}{|c|}{ Coefficient } & \multicolumn{4}{|c|}{ Marginal effects } \\
\hline & CSPC & HP & CSP & CSPC & DP & HP & CSP \\
\hline \multirow[t]{2}{*}{ Nomber enf year ts $<5 \mathrm{~A}$} & $-2,000 * *$ & $-1.627 * *$ & $-1.384 * *$ & $-0.0744 *$ & $0.0253 *$ & $-0.0115 *$ & $-0.0606^{*}$ \\
\hline & $(0.799)$ & $(0.794)$ & $(0.676)$ & $(0.0739)$ & $(0.0136)$ & $(0.0393)$ & $(0.0802)$ \\
\hline \multirow[t]{2}{*}{ Nomber enfants with fever } & 0.384 & -1.028 & -1.214 & 0.186 & 0.0166 & -0.00486 & -0.198 \\
\hline & $(1.438)$ & $(1.222)$ & $(1.224)$ & $(0.142)$ & $(0.0208)$ & $(0.0658)$ & $(0.157)$ \\
\hline \multirow[t]{2}{*}{ Ears. Disease } & $2,143 *$ & 1,725 & 1,868 & 0.0387 * & -0.0323 & $0.00966 *$ & $0.00322 *$ \\
\hline & $(1.140)$ & $(1.072)$ & $(1.140)$ & $(0.0581)$ & $(0.0222)$ & $(0.0337)$ & $(0.0718)$ \\
\hline \multirow[t]{2}{*}{ Mother's Orphan Stat } & 2,668 & $-13.34^{* * *}$ & 1,693 & $0.187 *$ & -0.0145 & -0.138 & $0.0347 *$ \\
\hline & $(2.043)$ & $(1.906)$ & $(1.612)$ & $(0.314)$ & $(0.00979)$ & (.) & $(0.314)$ \\
\hline \multirow[t]{2}{*}{ Orph elins 2 Parents } & 1,071 & $19.33^{* * *}$ & $18.49 * * *$ & $0.197^{* *}$ & -0.0253 & 0.108 & 0.115 \\
\hline & $(2.994)$ & $(2.489)$ & (2.631) & $(0.0684)$ & $(0.0186)$ & $(0.280)$ & $(0.289)$ \\
\hline \multirow[t]{2}{*}{ Adoptive } & -0.469 & -0.165 & $16.80 * * *$ & $-0.163^{* *}$ & -0.0203 & -0.0820 & $0.265^{* * *}$ \\
\hline & $(1.896)$ & $(1.873)$ & $(2.127)$ & $(0.0586)$ & $(0.0155)$ & (.) & $(0.0666)$ \\
\hline \multirow[t]{2}{*}{ Extended family } & $17.46^{* * *}$ & -0.946 & $15.36^{* * *}$ & $0.456^{*}$ & -0.0245 & -0.101 & $0.330 *$ \\
\hline & $(1.609)$ & $(1.450)$ & $(1,700)$ & $(0.287)$ & $(0.0185)$ & (.) & $(0.287)$ \\
\hline \multirow[t]{2}{*}{ Sick sex M } & 0.398 & -0.799 & -0.811 & 0.158 & 0.0110 & -0.0132 & -0.156 \\
\hline & $(1.148)$ & $(1.192)$ & $(0.988)$ & $(0.111)$ & $(0.0209)$ & $(0.0596)$ & $(0.117)$ \\
\hline \multirow[t]{2}{*}{ Sick child age } & $-0.177 * *$ & $-0.135 *$ & $-0.196 * *$ & -0.00126 & $0.00321^{*}$ & $-0.00357^{*}$ & $-0.00805^{*}$ \\
\hline & $(0.0745)$ & $(0.0716)$ & $(0.0793)$ & $(0.00295)$ & $(0.00146)$ & $(0.00160)$ & $(0.00409)$ \\
\hline \multirow[t]{2}{*}{ Illness severity } & $-2.069 *$ & 0.0624 & -1.504 & $-0.0862 *$ & 0.0250 & $0.105^{* *}$ & -0.0443 \\
\hline & $(1.456)$ & $(1.376)$ & $(1.349)$ & $(0.100)$ & $(0.0233)$ & $(0.0402)$ & $(0.111)$ \\
\hline \multirow[t]{2}{*}{ Pallor } & $-6.214 * *$ & $-6.204 * * *$ & $-6.656^{* * *}$ & -0.0786 & $0.718^{* *}$ & -0.0393 & $-0.600^{* *}$ \\
\hline & $(2.419)$ & $(2.211)$ & $(2.272)$ & $(0.0881)$ & $(0.226)$ & $(0.0321)$ & $(0.184)$ \\
\hline \multirow[t]{2}{*}{ Urine cola } & -2.255 & $-3.407 * *$ & $-3.355 * *$ & -0.120 & 0.158 & -0.0256 & -0.252 \\
\hline & $(1.528)$ & $(1.340)$ & $(1.488)$ & $(0.151)$ & $(0.145)$ & $(0.0504)$ & $(0.196)$ \\
\hline \multirow[t]{2}{*}{ Jaundice } & $-3.140 *$ & $-3.702 * *$ & $-3.261 * *$ & -0.0108 & 0.191 & -0.0363 & -0.144 \\
\hline & $(1.662)$ & $(1.755)$ & $(1.609)$ & $(0.0998)$ & $(0.165)$ & $(0.0415)$ & $(0.186)$ \\
\hline \multirow[t]{2}{*}{ Complication } & $-14.15 * * *$ & $-14.76^{* * *}$ & $-13.55 * * *$ & -0.0646 & 0.0286 & -0.114 & -0.150 \\
\hline & $(1.484)$ & $(1.843)$ & $(1.774)$ & $(0.194)$ & $(0.0222)$ & $(0.220)$ & $(0.322)$ \\
\hline \multirow[t]{2}{*}{ Constant } & $26.26^{* * *}$ & $24.73^{* * *}$ & $28.38^{* * *}$ & -0.0744 & & & \\
\hline & (5.157) & $(5.348)$ & $(5.346)$ & & & & \\
\hline $\operatorname{Pr}$ & & & & 0.14 & 0.02 & 0.07 & 0.87 \\
\hline LR STAT (37) & 57,128 & & $\mathrm{pr}=0.05$ & & & & \\
\hline$-\ln L$ & $-102,444$ & & & & & & \\
\hline Pseudo- R 2 & 0.254 & & & & & & \\
\hline AIC: & 3.303 & & & & & & \\
\hline BIC: & -0.612 & & & & & & \\
\hline NOT & 80 & 80 & 80 & 80 & 80 & 80 & 80 \\
\hline
\end{tabular}

Table 4: Characteristics of children in the explanation of the choices of modern structures.

Legend: CSPC: Public Health Center; CSP: Private Health Center; DP: Private Dispensary; HP: Hospital. 
Use of care and therapeutic route according to Health facilities

The different HF having constituted the modern use care options listed are: CS prived, public CS, private clinics and hospitals.

Therapeutic roaming shows that households first use the private health center with an average probability of $0.53(0)$ that the event occurs, then the public health center with a probability of 0.26 ( ), then private dispensaries 0.110 and finally the hospital 0.10() .

Table 5 presents the alternatives for access to care and the route for seeking care for children under 5 in the Bagira ZS.

\begin{tabular}{|c|c|c|c|c|}
\hline & \multicolumn{3}{|c|}{ Global probabilities } \\
\cline { 2 - 5 } & CSPC & DP & HP & CSP \\
\hline $\begin{array}{c}\text { Factors linked to the household } \\
\text { and its manager in explaining the } \\
\text { choices for using modern struc- } \\
\text { tures }\end{array}$ & 0.25 & 0.18 & 0.08 & 0.49 \\
\hline $\begin{array}{c}\text { The reasons for the choices of the } \\
\text { person in charge in the explanation } \\
\text { of the choices of use of modern } \\
\text { structures }\end{array}$ & 0.22 & 0.14 & 0.06 & 0.58 \\
\hline $\begin{array}{c}\text { Factors associated with structures } \\
\text { in explaining choices for using } \\
\text { modern structures }\end{array}$ & 0.46 & 0.09 & 0.24 & 0.21 \\
\hline $\begin{array}{c}\text { Characteristics of children in ex- } \\
\text { plaining choices for using modern } \\
\text { structures }\end{array}$ & 0.14 & 0.02 & 0.07 & 0.87 \\
\hline
\end{tabular}

Table 5: Use of care and therapeutic roaming according to the Health facilities

\section{Discussion}

We discuss in the following paragraphs specific determinants identified, related to seeking care for children under 5 suffering from malaria for years HZ Bagira to s has seen knowledge of antimalarial treatments instead of knowledge, method of payment for care, patient follow-up, distance from health facilities, number of sick children under 5 in a household, severity of the disease, age of sick children under 5 .

Parents who know antimalarial drugs would use more, for the care of their children, the public health center, hospital and private health center with the probabilities of $24.50 \%$ and $6.96 \%$. This is because, for some of them, participation in the care of their child begins with knowing the treatment that their child will face. This constitutes a factor of loyalty to health facilities knowing that knowledge of a remedy expresses its need; it is also necessary to point out the role of the level of education in the knowledge of antimalarial drugs $[19,24,25]$.

The failure to use care not modern, reduces the probability of use of private clinics $17.3 \%$; This is because the failure of nonmodern treatment is noted by complications and/or by the persistence of fever and in this case, parents prefer to bring sick children directly to HF with a higher technical platform (CS or Hospital) to the detriment of private dispensaries given the deterioration of the child's condition $[24,26]$. This confirms the literature which shows that most febrile children under 5 only go to the hospital for complications [25].

Those who go into debt with relatives to pay for child care are $12.70 \%$ less likely to resort respectively to the public health center compared to the private dispensary which has a solidarity character in terms of facilities. Several studies mention the economic constraints faced by households and the fact that, whatever its form, direct payment excludes a large number of people from care $[11,14,27,28]$.

Each additional kilometer away from the family home from the care structure starting from the normal distance (5 kilometers) reduces the probabilities for a household by $0.29 \%, 7.18 \%$, $2.47 \%$ of using public, private and public health centers. to the hospital for private clinics (4.42\%) due to their proximity to the household 's knowing that the distance between the house and the clinic, lost time at the facility are determining factors for choosing remedy $[11,29,30]$.

When the direct lump sum payment is offered by the public health center, hospital, private health center, the latter have respectively less than $4.30 \%, 13.40 \%$ and $26.60 \%$ probability of being used than the private dispensaries which offer the dropper package (in installments) or deferred. Given the socioeconomic situation of this population, the majority living from hand to mouth, heads of households prefer to pay medical costs in installments. This would allow the poor to have access to immediate medical care [31]. 
The additional improvement in the quality of care according to household perceptions in terms of reception, waiting time, efficiency and availability of drugs at the public health center and at the hospital increases their likelihood of recourse $(24.80 \%$ and $7.55 \%$ ) to the detriment of private dispensaries and private health centers. This is linked to the fact that quality allows the use of care and is one of the principles of organization of health services (improvement of services, acceptability and availability) [32,33]. The high attendance at dispensaries is thought to be the result of the deterioration in quality in public health facilities [34].

When a health structure monitors patients at home, it is the most used, since it is observed that when the private dispensary offers monitoring of sick children during and after treatment, the probability of seeking care increases by $99.70 \%$ in to the detriment of other health facilities that do not carry out this monitoring. These results show the role of home follow-up service that has been little exploited in other studies.

The increase in episodes of illness for the same period in a household reduces by $3.23 \%$ the probability of using a private dispensary in favor of other health facilities. This is because the private dispensaries used as a first resort have shown their limits and it would become imperative to resort to other health authorities; hence the delay and serious condition in which sick children are brought to appropriate facilities for care, as some authors have also demonstrated [8].

Comparing the child biological status (from the conjugal union of this household) to others, it appears that, the orphan 's two parents, most of opportunity compared to other children to access either the public health center or the private health center or is still in the hospital $(19.70 \%, 11.50 \%, 10.80 \%)$. This could be explained by the fact that they would be considered indigent in certain care structures and that several solidarity interventions in their favor would be organized. There in spring as discrimination which shows that children biological benefit of more favors and go into the structures with the best conditions of care, it is noted that the marginalization of other children especially if the adoption was in effect, without legal support.

The increase in the number of years favors the use of private dispensaries with the probability of $0.32 \%$ compared to other health facilities, which are used more by young children. This because for some parents, the lower age would be a protective factor [27]. As some have shown, age is a determining factor in deciding whether or not to seek treatment [35] according to priority, since it involves several sick children at the same time.

The severity of childhood malaria increases by $2.50 \%$ and by $10.50 \%$ the probabilities of using private clinics and hospitals to the detriment of other health facilities. These results could be explained from the angle of the negotiable cost and the absence of notable technical differences between Health Centers (HCs) and dispensaries and/or effective care in hospital knowing that severity would be positively associated with the use of care $[24,25,36]$. For some parents, the severe forms are perceived as a manifestation of the evil eye and will not go to the hospital until the end of the therapeutic route chain [37]. The severity of childhood malaria increases by $2.50 \%$ and by $10.50 \%$ the probabilities of using private clinics and hospitals to the detriment of other health facilities; These results could be explained from the angle of the negotiable cost and the absence of notable technical differences between HCs and dispensaries and/or effective care in hospital knowing that severity would be positively associated with the use of care [25]. For some parents, the severe forms are perceived as a manifestation of the evil eye and will not go to the hospital until the end of the therapeutic route chain [37].

Overall, the probability that households would use the private health center first in normal situations was 53\%, the public health center $26 \%$, the private clinic $11 \%$, and the hospital $10 \%$. This can be explained by the fact that private health centers are the majority in relation to public health centers, which would be unfairly distributed over the extent of the health zone. The hospital being expensive, it should normally collaborate with the first-line structures in terms of referrals and counter-referrals: these concepts seem to be deficient, testifying that health centers and dispensaries would take care of cases of severe malaria without prior authorization. This confirms what is reported by the literature: cases of severe malaria are often viewed with a negative view because of the belief in an evil power involved and that resorting to the hospital would be the last option [37].

Based on our results, in addition to the classic factors influencing the use of health care, our study emerges that the specific determinants for the use of care for children with malaria are knowledge of antimalarials (knowledge of a remedy reflecting the expression 
of need), monitoring of children with malaria during and after treatment (this strengthens parents' confidence and reassures them about the continuity of care); payment by lump sum and by installment and parental status of the child with malaria. These results therefore confirm our hypothesis [34].

This cross-sectional study, carried out, could have certain limitations, such as memory bias, the incorrect filling of certain survey questionnaires and the underestimation of information related to the socioeconomic situation. However, because it did not take into account the entire universe of determinants, a new study could well complete this information by favoring the mixed approach.

\section{Conclusion}

At the end of this work, it emerges that besides the classic factors intervening as influencing the use of care for children under 5 years old suffering from malaria, the follow-up of patients at home during and after treatment, appears as a capital variable, it is necessary to associate a pricing package by dropper (sliced). Knowledge of antimalarials should also be promoted in terms of an awareness campaign because of its influence on the use of care. The parental status of children must also attract the attention of decisionmakers as there is discrimination in the use of quality care.

This work therefore calls on decision-makers to look into improving the quality of care in health facilities with particular attention to monitoring patients at home and knowledge of antimalarials in order to improve the use of curative care among sick children under 5 years old with malaria in the Bagira Health Zone.

\section{Bibliography}

1. Unicef. "La situation des enfants dans le monde 2016". L'égalité des chances pour chaque enfant. Unicef New York (2016).

2. UNDP. Sustainable Development Goals. United Nations Develop Program. One United Nations Plaza, New York, NY 10017 (2016).

3. Revil H. "Le non-recours aux soins de santé". La vie des idées2014-laviedesidees fr (2014).

4. Franckel A. "Famille et recours aux soins dans l'enfance: le cas du paludisme à Niakhar (Sénégal)". Santé et bien-être des enfants, Neuilly sur Marne: PAO Assistance (2006): 706-18.

5. L'UNICEF IFdN. “Objectifs de développement durable” (2015).
6. Baxerres C., et al. "L'automédication et ses determinants". L'automédication et ses déterminants (2015).

7. Espenshade P and Selinger A. "Subverting the Concept of Self Medication in Addiction Recovery". L'automédication en question: un bricolage socialement et territorialement situé 11,12 et 13 mai 2016, Nantes (2016): 88.

8. Greenwood BM. "Morbidité et mortalité paludéennes en Afrique: éditorial. Bulletin de l'Organisation mondiale de la santé: la revue internationale de santé publique: recueil d'articles" 2 (2000): 1-2.

9. Barholere-Kulimushi V. "Promotion de la santé, itinéraires thérapeutiques et marché de la santé au Sud-Kivu". Pratiques locales, enjeux et perspectives. Mémoire RESO-EDUS [d'Éducation pour la Santé], Bruxelles, Université Catholique de Louvain (1999).

10. Kofoed P-E., et al. "Which children come to the health centre for treatment of malaria?" Acta Tropica 90.1 (2004): 17-22.

11. Diallo M. "Connaissances, attitudes et pratiques des mères face au recours précoce aux soins des enfants fébriles de 0 à 5 ans dans la sous-préfecture d'Abomey-Calavi". Mémoire de santé publique (1996).

12. Unicef. "Mise à l'échelle nationale de la prise en charge à domicile du paludisme: de la recherche à la mise en oeuvre". Mise à l'échelle nationale de la prise en charge à domicile du paludisme: de la recherche à la mise en oeuvre (2005).

13. MSP-RDC. "Plan National de Développement Sanitaire 20162020: Vers la couverture universelle des soins". Ministère de la Santé Publique (2016).

14. Kabinda JM., et al. "Analyse des modalités de financement des soins de santé en République démocratique du Congo". Annals of African Medicine 12.2 (2019): e3203.

15. CCSC-RDC. "Couverture Sanitaire Universelle (CSU): comment financer l'inclusion du secteur informel en République Démocratique du Congo (RDC)?". Centre de Connaissance en Santé (2017).

16. Karemere H., et al. "Analysis of hospital performance from the point of view of sanitary standards: study of Bagira General Referral Hospital in DR Congo". Journal of Hospital Management and Health Policy 4 (2020).

17. Aubin M-V. "Capitalisation des projets MSF-OCG dans le Sud Irumu, Ituri, RDC”. Médecins Sans frontières (2018). 
18. Namegabe EN. "Facteurs influençant le choix des soins au niveau des ménages dans la ville de Goma (RDC) Cas de 369 Ménages vivant dans les sites de partenariat de la FSDC/ ULPGL". Mémoires Université Libre des Pays des Grands Lacs (2008).

19. Philippe CM., et al. "Facteurs déterminants la faible utilisation par le ménage du service curatif dans la zone de santé de Pweto, province du Katanga, République Démocratique du Congo en 2013". Pan African Medical Journal 21.1 (2015).

20. ZS-Bagira. "Plan opérationnel de la Zone de santé de Bagira”. Zone de santé de Bagira (2019).

21. ZS-Bagira. "PLan de développement de la Zone de santé de Bagira 2015-2019”. Zone de santé de Bagira (2015).

22. Afsa C. "Le modèle Logit: théorie et application” (2016).

23. Ai C and Norton EC. "Interaction terms in logit and probit models”. Economics Letters 80.1 (2003): 123-129.

24. Audibert M. "Lutte contre le paludisme: approche économique des obstacles à son contrôle (Commentaire)". Sciences Sociales Et Santé 22.4 (2004): 25-33.

25. Audibert M., et al. "Utilisation de services de sante de premier niveau au Mali: analyse de la situation et perspectives". The World Bank (2005).

26. Houéto D., et al. "Fièvre chez l'enfant en zone d'endémie palustre au Bénin: analyse qualitative des facteurs associés au recours aux soins". Sante Publique 19.5 (2007): 363-372.

27. Ustrup M., et al. "Potential barriers to healthcare in Malawi for under-five children with cough and fever: a national household survey". Journal of Health, Population, and Nutrition 32.1 (2014): 68.

28. Rutherford ME., et al. "How access to health care relates to under-five mortality in sub-Saharan Africa: systematic review". Tropical Medicine and International Health 15.5 (2010): 508519.

29. Buor D. "Analysing the primacy of distance in the utilization of health services in the Ahafo-Ano South district, Ghana". The International Journal of Health Planning and Management 18.4 (2003): 293-311.

30. Stephenson R., et al. "Contextual influences on the use of health facilities for childbirth in Africa". American Journal of Public Health 96.1 (2006): 84-93.
31. Abdu Z., et al. "The impact of user fee exemption on service utilization and treatment seeking behaviour: the case of malaria in Sudan". The International Journal of Health Planning and Management 19.1 (2004): S95-S106.

32. Karemere H., et al. "Une expérience d'implantation des sites des soins communautaires en République Démocratique du Congo [Integrated community case management: An experience from the Democratic Republic of Congo]". International Journal of Innovation and Applied Studies 20.1 (2017): 42-51.

33. Karemere J., et al. "Associating the scale-up of insecticidetreated nets and use with the decline in all-cause child mortality in the Democratic Republic of Congo from 2005 to 2014". Malaria Journal 20.1 (2021): 1-13.

34. Kuamba E., et al. "Déterminants prioritaires de l'accès aux services des soins de la Zone de santé de Bagira pour les enfants de moins de 5 ans atteints de paludisme: Un protocole d'étude". International Journal of Innovation and Applied Studies 30.4 (2020): 808-820.

35. Rodriguez J and Wachsberger J-M. "L'automédication en République Démocratique du Congo: choix ou contrainte?" African Population Studies 30 (2016).

36. Banque-Mondiale. "Santé et Pauvrété en République démocratique du Congo". Banque Mondiale (2007).

37. Fourn L., et al. "Utilisation des services de santé par les mères des enfants fébriles au sud du Bénin". Santé Publique 13.2 (2001): 161-168.

\section{Volume 5 Issue 10 October 2021 (C) All rights are reserved by Hermès Karemere., et al.}

